\title{
Common accidents and precautions of Dry-type Air-core reactors
}

\author{
Xinnan Xie ${ }^{1}$, Jingyi Zhang ${ }^{1}$, Shuyi Tao ${ }^{1}$, Mei Xu ${ }^{1}$, Feng $\mathrm{Li}^{2}$, Yanhai Hang ${ }^{1}$, Lei \\ Zhang $^{1}$, Hui Tang ${ }^{1}$, Hui Miao ${ }^{1}$, Ying Li $^{1}$ \\ ${ }^{1}$ Fushun power supply company, State Grid Liaoning Electric Power Co., Ltd. \\ ${ }^{2}$ Information and Communication Branch,State Grid Liaoning Electric Power Co., Ltd.
}

Keywords: dry-type; air-core reactors; magnetic leakage; excessiveheating; turn-to-turn faults; tree discharge

\begin{abstract}
Reactors are widely used in power systems because of their important functions. Its series connection with reactors in the places where outlet breakers are can increase short-circuit impedance and limit short circuits' current. And its parallel connections with capacitors in wave filters can limit harmonics of electrified wire nets. And running voltages can be adjusted by adjusting paralleling reactors. The passage briefly introduced the developing history, trengths and weakness of six kinds of reactors including cement hollow reactor ,oil immersed reactor core, dry-type air-core reactor, dry core reactor ,dry type half core reactor and dry hollow magnetic shielding reactor. It specially discusses the performance of dry type air-core reactors and the attentions in use. Meanwhile it sets forth the common accidents that present in dry type air-core reactors such as interphase short circuit, harmonics, temperaturerise, pollution flashover, magnetic leakage, dendritic discharge and turn-to-turn faults and it proposes some precaution as well.
\end{abstract}

\section{Introduction}

Reactors, also known as inductance coils (L),are widely used in power systems. Generally speaking, reactors are electric apparatus which play impedance roles in electric circuits. Reactors used in power systems are divided into iron core reactors and air core reactors according to if there are iron cores in their windings. The structures of oil immersed iron core reactors are similar to voltage transformers, which consist of coils, ironcores, fuel tanks and so on. Actually, dry-type air-core reactors are air-core coils without magnetic material .[1]

Reactors are widely used in power systems because short circuit current in the systems are bigger and bigger with the increasing magnification of the load. It is very difficult to keep dynamic stability and thermal stability of electric apparatus without limitation. In order to satisfy the demand of circuit devices' breaking capacities, it's necessary to take the following measures: Reactors should be in series in the places where outlet breakersare; enlarge short-circuit impedance; limit short-circuit current; be in series with or parallel capacitors in wave filters to limit harmonics in electrical net; adjust operating voltages by adjusting the number of shunt reactors; usephase-controlled reactors to make sure the accuracy of TCR's regulating control performances in SVC.[5]

\section{The types of reactors}

According to the developing process, there are six kinds of series reactors in order: cement hollow reactor, oil immersed iron-core reactor, dry-type air-core reactor; dry core reactor, dry-type half core reactor and dry hollow magnetic shielding reactor.

\section{Cement hollow reactor}

There is no iron core in its structure and its coil is enveloped with cement. This reactor is very big. The reactor has no iron core magnetic saturation, so its iss inductance is linear. That means its iss inductance doesn't change with the size of electric current, which is its merit. While its weakness is its big magnetic flux leakage, largeloss, largearea, poorappearance, difficult installation and maintenance and difficulty for outdoor. Atpresent, cement hollow reactors are obsoleted basically 
except very few cases.

\section{Oil immersed reactor core}

Oil immersed reactor core came up in early 1980s and its structure is similar with oil-immersed transformer. It's mainly made up of iron core, coil and clamping device. Oil immersed reactor core is small with the merits of small magnetic flux leakage, small loss and its small area. While its weakness is:

(1)Iron core is saturated when there is a high voltage or a high current and its iss inductancedeclined, soshunt compensation can greatly reduce the excitation inrush current

(2)In order to keep iron core from being supersaturated, the core limb is divided into pieces and air gaps must be left between every two pieces. As a result, another problem follows: both the noise and vibration are bigger than the transformer of the same capacity. Bigger vibration can loose reactors'mechanical connection, so theiss inductance change with it.

(3)The impact ability of short current is not strong, that's because its coil isn't enveloped but immersed in the oil directly. Thecoilis only compacted by heel blocks and braces and it lack enough mechanical strength, so this kinds of reactors aren't suitable to be fixed in front of capacitors (main sides).Or when some point meets earth short circuit, huge short-circuit current will totally traverse core resistance and cause reactors' damage.

(4)The reactors contain oil, so some possibilities such as oil leak v flammability and explosiveness are unavailable and it's difficult to maintain the reactors.[3]

\section{Dry-type air-core reactors}

In early 1990s,dry-type air-core reactors emerged as the time require. They were made up of coils aluminum rows without cores or oil. The coils are enveloped with epoxy resins and glass fiber. They basically overcome the main shortcomings of oil immersed reactor core with good reactance linearity, low noises and good heat radiation. They can be used both indoors and outdoors. But the reactors ' shortcoming is the big magnetic leakage. Enough magnetic safe distance is necessary in the process of installment in order to decrease the influence of magnetic leakage, so this kind of reactors occupy more area and they have big height in the process of lamination. The general rule is that there mustn't be metal closed loop or big metallic conductor in the distance of 1.7D between every two reactors,1.1D around and $0.5 \mathrm{D}$ in the upper and lower ranges. The rule of 1.7D is to decrease the mutual inductance among the reactors while the latter is to avoid metalwork 's high temperature that reactors cause when they lead eddy current loss in metal closed loop or big metallic conductors.

\section{Dry core reactor}

Dry core reactor's iron core and clamping device are the same as the ones of oil immersed reactor core. And its coil is the same as dry type transformer, it is made by vacuum pouring of epoxy resins. Compared with oil immersed reactor, dry core reactor is not only oil-free, but its resistance to short circuit current is higher. Its merits are small area, lowloss, small magnetic leakage and dry oil-free, while its shortcoming is when the reactor deeply saturated, itsiss inductancedecreases, restrictions on inrush current is limited and its noises and vibration are bigger than those of oil immersed reactor core. This reactor is used indoors. If it is used outdoors, it must be added with protective skin.[3]

\section{Dry type half core reactor}

In late 1990s,dry type half core reactor came out. Iron core is added in the center of air-core reactor and the iron core is cast formed and then solidified with coil into an integrated whole without problem of noises and looseness. Its structure is the same as the one of air-core reactor and it can be used outdoors. Compared with air-core reactor, besides the merits such as good reactance linearity, strong resistance to short-circuit current, smallnoises, dry type half core reactor has the following advantages: fifty percent volume, seventy-five area and sixty to seventy loss. Its weakness is that it still can't solve the problem of big magnetic leakage and bigger magnetic safe distance is necessary in the process of installment.[2]

\section{Dry hollow magnetic shielding reactor}

At the beginning of the twenty-first century, a new magnetically shielded series reactor was 
launched to the market. It not only adds an iron core in the center of air-core reactor coil but also adds a magnetic core ring on the outermost surface. Its shielding principle is to concentrate common magnetic lines of air resistance divergence in iron circuit by making use of characteristic of iron core's magnetoconductivity is bigger than air's, so that this method can dectease magnetic leakage greatly. In this series connection, except the consolidation of the iron core and the coil, its other parts'structure, material and the process of engineering are all the same as common air resistance's, soit has the merits of good reactance linearity, high mechanical strength and small noises.

\section{Reactors commonly used at present}

What power systems use most commonly is dry-type air-core reactors whose windings are many single-layer coil twined by aluminium conductor insulated withrespectively. Theplsces between two adjacent layers are insulated or heat-radiated with mylarpolyster or by putting air passage at intervals. Infact, the two adjoining levels have approximate electric potentials. Soinsrulation between two adjacent layers is more reliable. Afterthe winding is twined and dried, dip the polyesters and then solidify them. Put antimagnetic brackets which are similar with spider webs both on the top and at the bottom of it, use insulators and arm-braces under the brackets to make them fixed on ground under structure. The reinforcement bars in foundation concrete need to be insulated from each other and they can't compose return circuit, in order to prevent eddy current loss caused by mangneticliakage. In three-phase combination, reactors can be stacked up together, arranged levelly or arranged in the shape of triangles.

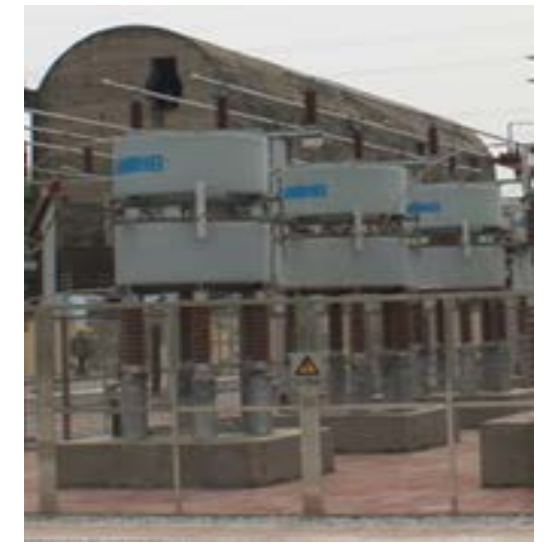

Fig. 1 horizontally arranged reactors

\section{Common faults of drg-type air-core reactor}

Because its birth defects in the design and manufacture, dry-type air-core reactor's accident rate is high in recent years. L The following picture is a turn-to-turn burnout accident because inappropiate manufacturing process reactors.

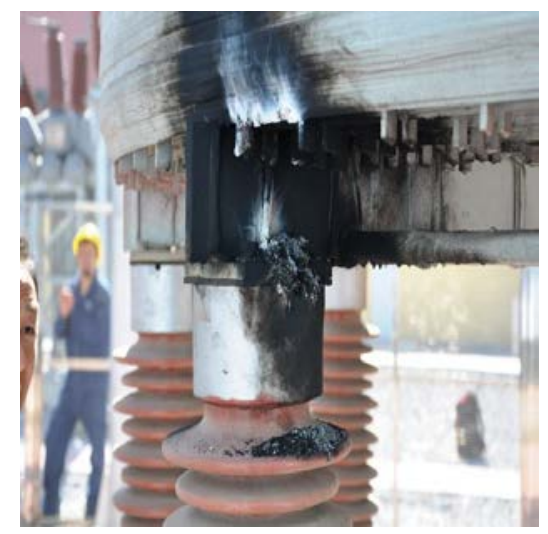

Fig. 2 reactor for generating interturn short circuit burning accident 


\section{Interphase short circuit}

Because dry-type air-core reactors have no out skin to cover themselves, especially the reactors of stacked structure, and their phase distances are close, it can cause interphase short circuit faults when small animals or big birds go into reactors, This not only damage the reactors, but also cause tripping operations of the main transformers, therefore large-area blackout happens.

\section{Turn-to -turn faults}

Reactors' turn-to-turn faults is the main reason of the damage of dry-type air-core reactor. Byanalyzing many reactor accidents, it can be known that because of process problems, mylarpolyster used in insulation will be damaged if there are somefaults such as cinder inclusion and burrs. Then a turn-to -turn fault happens in this place and it can cause local overtheating. In the effect of long-term heat history, local temperature is too high, which leads to insulation aging and constant expansion of turn-to-turn fault area.This leads to the constant expansion of reactors packing currents, as a result ,penetrating burn from bottom totop happens and aluminium conductor snapped. Meanwhile, burn insulation of two adjacent encapsulation.

\section{Tree discharge}

Reactor coils are insulated externall by solidifying epoxy resins. The coils' surface insulation strength can't be compared with apparently smooth and uniform insulator. Because of coils' effect on earth capacitance and turn-to-turn capacitance ,voltage is not evenly distributed. Becausebing effected by humidity and filth, in the place where prtentialgradiant on reactor surface is high air flash discharges corona that is formed locally and dissociately and branches which move quicly under the action of uneven electrifield. When air dissociates, it will decompos some ozone and carbonic oxide, both of which combin with water on insulation surface and nitric acid and nitrous acid are produced. They corrode insulation and carbonized it, as a result ,deep grooves are formed on the surface of the insulation and this decrease the insulation strength. Gradually, the noises when reactors run is gigger and reactors themselves become lloose, which lead to creepage along braces and there will be tree charges on the surface of reactors'coils, and it can lead to reactor burn.

\section{Magnetic flux leakage}

Dry-type air-core reactors, because iron core has no rules to magnetic flow, and no magnetic shielding measures can be taken there is strong magnetic field around reactors. There are ground screens in reactors' axial position, and there are equipments, obstructions and frames in radial position. They all can cause serious magnetic leakage problems because metal bodies constitute closed loop and lead to bad influences on surroundings. Magnetic leakage can perceive currents that is hundred times, which not only enlarge reactors'loss, but also cause serious problems because of the coupling of its reverse field and reactors' part winding. Forexample, a closed loop in radial position may make reactor's winding overheating, while a closed loop in axial position may lead to reactor's enlargement and change of postential distribution.

\section{Pollution flashover}

After three years operation in outdoor atmospheric conditions, there can be dirt deposit on reactor's surface, and insulation material painted on the surface may be pulverized which lead to another kind of dirt bed. When there is drizzle or densfog, the dirt bed will be damped which can lead the enlargement of the surface leakage current and generate heat. Because of the uneven distribution of electric field strength on reactor's surface, the water evaporates faster in the areas where electric field concentrates. This lead to dry arc areas in surface parts and in these places voltages are widely distributed and cause partial discharges. Electric arc will develop, merge and form dendritic discharge in the surface. Whendendritic dischargealong the surface run through two poles, pollution flashover happens.

\section{Temperature rise}

Because of the high temperature in some point of the coil in the runningrocess, mylarpolyster's aging accelerates, so that the mylar loses insulating property and reator's life length is decreased.The main reasons that cause temperatuse rise not enough design margin of temperature rise is gotten'in the manufacturingprocess, when winding is wound, There are not enough counterweights of spool and winding speed is not even sometimes it is too rapicl and sometimes 
there is a machine hoult .This causes bad winding tightness and change of wire-wound resistor. If the choise of winding diameter gets closer to target limit, resistance value of reactors sill get lower. Because reactor's rated current is higher, the load losses increase and the heat produced in operation exceeds the limit. The welding resistance between connectiong terminal and winding weld leads to resistance increase because of welding quality, and it leads to temperature rise.

\section{Harmonic}

With the constant network operations of non-linear load such as metallurgy, coal, chemical industry and electrified railway ,the electricity process will produce lots of harmonic injected into network. Forreactors, harmonic my cause reactors and capacitive equipments in LAN to lead to harmonic amplification. It can even lead to resonance oscillation in solemn hours and reactor burnout accidents.

\section{Conclusion}

In order to avoid dry-type air-core reactor accidents, we should take the following precautions, keep small animals or big birds going into reactors; enhance manufacture process. If there are some faults such as cinder inclusions or burrs, mylarpolyster used in insulation may be damaged, which may cause turn-to -turn faults in the process of operation;running workers should strengthen inspections and take strict procautions against tree discharge on loop surface of reactors caused by braces becoming loose. Duringconstruction, there mustn't be transverse metal closure so that high temperature caused by magnetic leakage can be avoided; regularly clean the filter deposited on reactors' surfaces to put an end to pollution flashover accidents; pay attention to harmonic management and prevent harmonic from inflowing electrified netting and damaging reactors.

\section{References}

[1] Wang Zhaoan, YangJun,LiuJinjun etc. harmonic suppression and static Var Compensator[M] China Machine Press

[2] Jiang Jiajiu TCA type SVC thyristor controlled reactor preference[J]High Power Converter Technology 2009

[3] Shiping Liu Guiying Static Aeactive Power Compensation technology [M]China Electric Power Press.2006

[4] JinLongzhang.DingYushan.Practical Technology of Reactive Power Compensation.China Water Power Press.1997

[5] Chen Cixuan Overvoltage Protedion Principle and Operation Technology.China Electric Power Press.2002.6 